\title{
Holistic protocol for callus culture optimization using statistical modelling
}

\author{
Tiago Fidemann, Gabriela Aparecida de Araujo Pereira, Lia Bossard \\ Nascimento, Milena Cristina Moraes, Mônica Rosa Bertão, Regildo Márcio \\ Gonçalves da Silva \& Eutimio Gustavo Fernández Núñez
}

To cite this article: Tiago Fidemann, Gabriela Aparecida de Araujo Pereira, Lia Bossard Nascimento, Milena Cristina Moraes, Mônica Rosa Bertão, Regildo Márcio Gonçalves da Silva \& Eutimio Gustavo Fernández Núñez (2018) Holistic protocol for callus culture optimization using statistical modelling, Natural Product Research, 32:9, 1109-1117, DOI: 10.1080/14786419.2017.1380026

To link to this article: https://doi.org/10.1080/14786419.2017.1380026

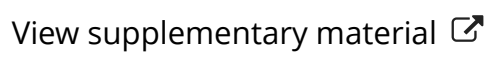

曲 Published online: 28 Sep 2017.

Submit your article to this journal $\pi$

Џll Article views: 105

View Crossmark data $₫$

Citing articles: 1 View citing articles $₫$ 


\title{
Holistic protocol for callus culture optimization using statistical modelling
}

\author{
Tiago Fidemanna , Gabriela Aparecida de Araujo Pereira ${ }^{a}$, Lia Bossard Nascimentoa, \\ Milena Cristina Moraes a , Mônica Rosa Bertão ${ }^{a}$, Regildo Márcio Gonçalves da Silva ${ }^{a}$ and \\ Eutimio Gustavo Fernández Núñez ${ }^{\mathrm{b}}$ (D)
}

aFaculdade de Ciências e Letras, Departamento de Biotecnologia, Universidade Estadual Paulista (UNESP), Assis, Brazil; 'bentro de Ciências Naturais e Humanas (CCNH), Universidade Federal do ABC, Santo André, Brazil

\begin{abstract}
Plants endue a key role againstillnesses caused by oxidative stress. These attributes are frequently associated with polyphenolic compounds. However, presence and concentration of secondary metabolites are affected by abiotic factors. The in vitro culture techniques can solve these drawbacks. Peppers can be a suitable alternative to obtain polyphenols. Aiming to optimise the callus culture stage from Capsicum baccatum to produce polyphenols, this work evaluated systemically the effects of the explant's origin (root, hypocotyl and cotyledon), growth hormone type (2,4-dichlorophenoxyacetic acid $(2,4-\mathrm{D})$, benzylaminopurine (BAP) and a combination of 2,4-D/BAP at five-to-one ratio) and concentration $\left(0.023-10.000 \mathrm{mg} \mathrm{L}^{-1}\right)$ on callus culture efficiency parameters using a multilevel factorial design. The root explant in combination with BAP at $1.138 \mathrm{mg} \mathrm{L}^{-1}$ ensured the optimal values of the assessed responses; callus mass (225.03 mg), antioxidant activity (35.95\%), total phenols (11.48 mg of GAE/g DE) and flavonoids (15.92 $\mathrm{mg}$ of RU/g DE) production.
\end{abstract}

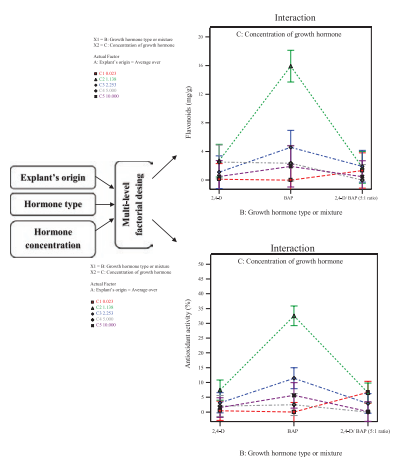

\section{ARTICLE HISTORY}

Received 20 July 2017

Accepted 1 September 2017

\section{KEYWORDS}

Antioxidant activity; bioprocess optimisation; Capsicum baccatum; plant cell culture; polyphenolic compounds; statistical experimental designs

CONTACT Eutimio Gustavo Fernández Núñez eutimiocu@yahoo.com

(4) Supplemental data for this article can be accessed at https://doi.org/10.1080/14786419.2017.1380026. 


\section{Introduction}

The oxidative stress and inflammations are associated with many diseases such as diabetes, cancer, cardiovascular and neurodegenerative diseases causing concern worldwide (Zimmer et al. 2012). In that sense, the plants have played a key role due to their pharmacological properties against these disorders. These attributes are most of the times associated with the presence of polyphenolic compounds; among them, phenolic acids and flavonoids are highlighted (Ramkissoon et al. 2013). Specifically, flavonoids perform a wide range of functions such as UV-light protection, defence against phytopathogens and antioxidant activity (Petrussa et al. 2013).

Peppers, as are well known these horticultural species, have a wide variety of phytochemicals with antioxidant properties and can be a suitable alternative to obtaining these chemical structures. Among the peppers, the Capsicum genus, which is native to the tropical zones of Central and South America, stands out. Capsicum baccatum is one of five main domesticated pepper species, in which also include Capsicum annuum, Capsicum chinense, Capsicum frutescens and Capsicum pubescens (Zimmer et al. 2012).

As a rule, the presence of secondary metabolites (SM) and their phytochemical concentrations are affected by several environmental factors such as drought, temperature, altitude, salinity, metal ions, light and UV radiation (Verma and Shukla 2015). Another drawback, in obtaining them directly from plants, is related to the low natural disposition of these compounds. However, these problems can be solved with in vitro alternative techniques like plant cell and tissue culture methodologies. Many classes of SMs are synthesised, accumulated and sometimes exuded using some culture systems such as callus culture and cell suspension culture (Matkowski 2008).

In vitro plant cell cultures have several advantages for producing SMs compared with chemical synthesis or cultivated plant, such as controlled conditions for bioactive metabolite production (avoiding or lowering abiotic factors variance) and uniform quality and continuous supply of products using high-production cell lines. However, in vitro plant cell cultures are still under development and have some limitations including low yields, genomic instability and scale-up difficulties (Mustafa et al. 2011). Besides, up to date, the several factors that influence on biomass production and product accumulation in vitro plant cell culture are mainly studied and set using one-factor-at-a-time strategy, where the multiple interactions among process parameters are not taken into consideration (Schmitz et al. 2016).

Thus, the aim of this paper was to optimise the callus culture stage systemically as an initial step for developing a plant cell bioprocess to produce SMs with applications in food or pharmaceutical industries. The goals in callus culture optimisation were to increase the yield of callus mass, polyphenolic secondary metabolites and antioxidant capacity in extracts from the horticultural species cells, C. baccatum L. var. pendulum.

\section{Results and discussion}

The current study was performed to establish the initial stage (callus culture) of a biotechnology to produce SM from C. baccatum L. var. pendulum. The use of explants herein from seedling lay on the previous observations which confirmed that young tissue is more responsive to callus initiation than mature plant tissues (Malik et al. 2011). Besides, drastic tissue decontamination procedures and time-consuming and low-controlled protocols, when 
Table 1. Analysis of variance (ANOVA) for each response variable model. Probability values associated with the statistical significance tests for models, terms and model lack of fit of the coded response variables used to describe callus cultures stage are reported.

\begin{tabular}{|c|c|c|c|c|c|}
\hline \multirow[b]{2}{*}{ Source } & \multicolumn{5}{|c|}{ Response variables } \\
\hline & $\begin{array}{l}\text { Callus mass } \\
(\mathrm{mg})\end{array}$ & $\begin{array}{l}\text { Budding index } \\
(\%)\end{array}$ & $\begin{array}{l}\text { Antioxidant } \\
\text { activity (\%) }\end{array}$ & $\begin{array}{l}\text { Total phenols } \\
\left.\text { (mg GAE g }{ }^{-1} \mathrm{DE}\right)\end{array}$ & $\begin{array}{l}\text { Flavonoids (mg } \\
\text { RU } \mathrm{g}^{-1} \mathrm{DE} \text { ) }\end{array}$ \\
\hline Model significance & $<0.0001$ & $<0.0001$ & $<0.0001$ & $<0.0001$ & $<0.0001$ \\
\hline \multicolumn{6}{|l|}{ Term significance } \\
\hline A-Explant's origin & $<0.0001$ & $<0.0001$ & - & - & - \\
\hline $\begin{array}{l}\text { B-Growth } \\
\text { hormone type or } \\
\text { mixture }\end{array}$ & 0.0010 & - & $<0.0001$ & $<0.0001$ & $<0.0001$ \\
\hline $\begin{array}{l}\text { C-Concentration of } \\
\text { growth hormone }\end{array}$ & $<0.0001$ & $<0.0001$ & $<0.0001$ & $<0.0001$ & $<0.0001$ \\
\hline$A B$ & $<0.0001$ & $<0.0001$ & 0.0351 & 0.0031 & - \\
\hline$A C$ & 0.0179 & $<0.0001$ & - & - & - \\
\hline$B C$ & $<0.0001$ & $<0.0001$ & $<0.0001$ & $<0.0001$ & $<0.0001$ \\
\hline$A B C$ & 0.0058 & 0,0005 & - & - & - \\
\hline Lack of fit test & - & - & 0.9362 & 0.9552 & 0.8695 \\
\hline
\end{tabular}

Note: The symbol (-) represents the no significant statistical tests.

explants are taken from species in natural environments, were avoided. Among the 45 treatments (15 for each explant's origin), 13 did not form callus (Table S1). The failed experiments were distributed as follow: six in root explants, five in hypocotyl and two in cotyledon. The successful use of cotyledon in the present work as explant source for obtaining high budding indexes respect to other plant tissues utilised in vitro regeneration techniques has also been confirmed for other vegetable species, including Chilli peppers (Were et al. 2006; Kothari et al. 2010). This superiority may be related to the development of meristematic zones in subepidermal cells on the adaxial side of cotyledon explant (Motamedi et al. 2011). However, the hormone type and concentration can change this regularity (Kothari et al. 2010).

On the other hand, all models for response variables were significant, and the statistical assessment of the studied factors was also performed (Table 1) and discussed in detail below.

\subsection{Wet weight}

The callus mass varied widely among the assessed experimental combinations. The best result for root was $498.23 \mathrm{mg}$ using 2,4-D/BAP (5:1 ratio) at $1.138 \mathrm{mg} \mathrm{l}^{-1}$. Similarly, the highest callus mass $(862.43 \mathrm{mg}$ ) for hypocotyl was obtained utilising the same hormone mixture and concentration. However, for cotyledon, the best value of callus weight $(519.13 \mathrm{mg}$ ) was reached with 2,4-D at $2.253 \mathrm{mg} \mathrm{I}^{-1}$ (Table S1). It was also observed 2,4-D had a better response for cotyledon and similar response for root and hypocotyl. On the other hand, the effect of BAP utilisation in culture medium was similar in the three evaluated explants. Nevertheless, the 2,4-D/BAP had shown better response for hypocotyls and similar response for root and cotyledon (Figure S1A). Both hormones are quoted in callus formation due to their capacity in promoting cell division and growth. However, this higher response in calli using 2,4-D/ BAP can be related to the synergism during interaction between auxin and cytokinin (George et al. 2008).

It was confirmed superior performance in callus weight for hypocotyl and cotyledon explants when hormone concentration was in 1.138-2.253 $\mathrm{mg} \mathrm{I}^{-1}$ range, but the $1.138 \mathrm{mg} \mathrm{I}^{-1}$ concentration was more suitable for root explant (Figure S1B). On the other hand, the 
$1.138 \mathrm{mg} \mathrm{l}^{-1}$ concentration was the optimum value when the hormone mixture 2,4-D/BAP (5:1 ratio) was included in the culture medium (Figure S1C). These differences in the callus mass obtained at different concentrations and explant's origin can be related to the different sensibility of explant's origin; for example, roots are more sensitive than hypocotyls about auxin (2,4-D). Another point is that concentrations higher than the optimum are inhibitory. Besides, the quantity applied in the medium can influence the synthesis and degradation of endogenous hormones used in callus propagation (George et al. 2008).

\subsection{Budding ratio}

The budding ratio (\%) was evaluated to define its relationship with callus mass. It was confirmed a direct correlation between callus mass and the budding ratio (Table 1). The highest callus weights for each explant's origin of $862.43 \mathrm{mg}$ (hypocotyl); $519.13 \mathrm{mg}$ (cotyledon), $498.23 \mathrm{mg}$ (root) had $93.33,93.33$ and $86.67 \%$ budding ratio, respectively.

It was possible to observe the same hormone response in the use of BAP and 2,4-D/BAP for root, hypocotyl and cotyledon. The use of 2,4-D improved only budding index in cotyledon respect to hypocotyl and root explants. However, the growth hormone supplementation with BAP and 2,4-D/BAP at five-to-one ratio in explants from root and hypocotyl increased significantly the budding ratio (twofold higher than budding ratio for 2,4-D). Thus, it was possible to confirm a great likeness between callus mass and budding index models (Figure S1 A and Figure. S2), and so the hormone type/mixture and concentration seem to influence alike the processes of induction of callus from explants and stimulation of cell division.

The highest observed values of callus mass and budding ratio for a hypocotyl explant using 2,4-D/BAP is in harmony with results derived from a previous study carried out with C. annuum and the synergic effect of auxin and cytokinin hormones in callus culture (George et al. 2008; Kothari et al. 2010).

\subsection{Antioxidant activity}

The callus antioxidant activity (AA\%) showed significant differences in performance for each treatment. The ANOVA results showed no significant influence of explant's origin (Table 1). The growth hormones and their concentration resulted in different AA\%. For root, the AA\% varied from 1.14 to $41.48 \%$. For hypocotyl, this response varied from 1.47 to $9.56 \%$. On the other hand, in cotyledon, values of $A A \%$ were in $0.41-11.19 \%$ range.

BAP had better response in root and hypocotyl. However, there was no difference among the hormones for cotyledon (Figure S3A). On the other hand, the BAP used at $1.138 \mathrm{mg} \mathrm{I}^{-1}$ had an extremely better response (Figure S3B). The best treatment (root using BAP at $1.138 \mathrm{mg} \mathrm{l}^{-1}$ ), with $41.48 \%$, has a higher AA\% than a previous value that reported by Bertao et al. (2016) in C. baccatum fruits $-22.98 \%$ at $5.0 \mathrm{mg} \mathrm{l}^{-1}$ extract concentration (the same used is this study) and $32.89 \%$ at $10.0 \mathrm{mg} \mathrm{l}^{-1}$ extract concentration. Thus, it is demonstrated the suitability of the callus culture for producing SMs with antioxidant activities in Capsicum baccatum.

\subsection{Total phenols (TP)}

Total phenols varied widely (Table S1). As observed in AA\%, the ANOVA results (Table 1) showed no significant influence of explant's origin. Specifically, the TP values for root explant 
varied from 0.36 to $13.13 \mathrm{mg} \mathrm{GAE} \mathrm{g}^{-1} \mathrm{DE}$. For hypocotyls and cotyledons, values varied from 0.27 to $10.00 \mathrm{mg} \mathrm{GAE} \mathrm{g}^{-1} \mathrm{DE}$ and from 0.15 to $6.49 \mathrm{mg} \mathrm{GAE} \mathrm{g}^{-1} \mathrm{DE}$, respectively.

The interaction graph among explant's origin and growth hormone or mixture (Figure S4A) revealed that BAP had better response in the TP amount, except for cotyledon. The TP amounts obtained in the best treatment (using BAP at $1.138 \mathrm{mg} \mathrm{l}^{-1}$ ) were $13.13 \mathrm{mg} \mathrm{GAE} \mathrm{g}^{-1}$ DE for root, $10.00 \mathrm{mg} \mathrm{GAE} \mathrm{g}^{-1} \mathrm{DE}$ for hypocotyls and $6.48 \mathrm{mg} \mathrm{GAE} \mathrm{g}^{-1} \mathrm{DE}$ for cotyledon (Figure $\mathrm{S} 4 \mathrm{~B})$. The results follow the same pattern found in (AA\%) suggesting a correlation between both responses that has been quoted in recent researches about higher $A A \%$ related with TP (Zimmer et al. 2012; Ramkissoon et al. 2013). Krishnan et al. (2015) also reported for Gynura procumbens higher TP concentration in root callus than those values from other plant part callus (leaf with 0.483 , stem with 0.559 , and root with $0.891 \mathrm{mg} \mathrm{GAE} \mathrm{g}^{-1}$ Fresh Weight).

\subsection{Flavonoids}

The flavonoids did not vary widely among the treatments, except for four treatments using BAP (Table 2, Table S1). The treatments using 2,4-D and 2,4-D/BAP (5:1 ratio) showed flavonoids contents inferior to 5.0 ( $\mathrm{mg} \mathrm{RU} \mathrm{g}^{-1} \mathrm{DE}$ ). Conversely, BAP treatments varied from 8.89 to 20.44 ( $\mathrm{mg} \mathrm{RU} \mathrm{g}^{-1} \mathrm{DE}$ ).

The treatments with higher flavonoids content were similar to those with higher TP content and AA\% (Figure S3, Figure S4 and Figure S5), reasserting the relation of these compounds with antioxidant activity (Matkowski 2008). However, not all AA\% can be related only with TP or flavonoids, but also with other non-phenolic compounds like terpenoids (Ranilla et al. 2010).

\subsection{Optimisation}

The optimisation was done by desirability function; the factors under study were maximised, and an importance scale among the responses was attributed: callus mass (5), AA\%

Table 2. Experimental runs (15 for each explant's origin) associated with multilevel factorial design for modelling and optimising callus culture stage from Capsicum baccatum L. var. pendulum cells. All combinations were randomly performed in triplicate $(48.89 \%)$, in duplicate $(37.78 \%)$ or single sample (13.33\%).

\begin{tabular}{lcc}
\hline Explant's origin & Growth hormone type or mixture & Concentration of growth hormone $\left(\mathrm{mg} \mathrm{I}^{-1}\right)$ \\
\hline Root, Hypocotyl or Cotyledon & $2,4-D$ & 0.023 \\
& 1.138 \\
& 2.253 \\
& 5.000 \\
BAP & 10.000 \\
& 0.023 \\
& 1.138 \\
& 2.253 \\
& 5.000 \\
2,4-D/BAP (5:1 ratio) & 10.000 \\
& 0.023 \\
& 1.138 \\
& 2.253 \\
& 5.000 \\
\end{tabular}


(4), TP (3) and flavonoids (3). The budding was adjusted to the range due to its relation with callus mass. The best result was defined for root explant using BAP at $1.138 \mathrm{mg} \mathrm{l}^{-1}$. This factor set allows the best compromise among callus mass $(225.03 \mathrm{mg})$, antioxidant activity (35.95\%), total phenols (11.48 $\mathrm{mg} \mathrm{GAE} \mathrm{g}^{-1} \mathrm{DE}$ ) and flavonoids (15.92 $\mathrm{mg} \mathrm{RU} \mathrm{g}^{-1} \mathrm{DE}$ ) production. This result was obtained by avoiding the several abiotic factors that may reduce their concentration and unable to be realised the large-scale production (Verma and Shukla 2015).

\section{Experimental}

\subsection{Plant material}

The explants were obtained from C. baccatum L. var. pendulum (Cambuci) seedlings in vitro germinated (thereby avoiding disinfestation procedures). The seeds were obtained in a local market from Assis, São Paulo State $\left(-22^{\circ} 39^{\prime} 42^{\prime \prime} \mathrm{S},-50^{\circ} 24^{\prime} 44^{\prime \prime} \mathrm{W}\right)$. The voucher specimen (HASSI-01127) was deposited at the Herbarium Assisense of the Biology Department, UNESP, Assis, Brazil.

\subsection{Optimisation of callus culture}

The explants (in average $7 \mathrm{mg}$ ) were obtained from seedling (pretreated seeds with $1 \% \mathrm{KNO}_{3}$ aqueous solution $(\mathrm{w} / \mathrm{v})$ for $10 \mathrm{~min}$ and in vitro germinated in culture medium containing distilled water, $0.6 \%$ agar and 1.88 mg gibberellic acid $\mathrm{I}^{-1}$ ) with cotyledons' appearance. The plant parts used to obtain callus were roots, hypocotyls and cotyledons. Explants were cut and inoculated in Petri dishes $(15 \times 100 \mathrm{~mm})$ containing $35 \mathrm{~mL}$ Murashige and Skoog culture medium (MS) (pH 5.75) solidified with phytagel (Sigma Chemical Co., St. Louis, MO) $4 \mathrm{~g} \mathrm{I}^{-1}$ and supplemented with $3 \%$ sucrose and different growth hormone types ( 2,4 -dichlorophenoxyacetic acid (2,4-D) , benzylaminopurine (BAP) and a combination of 2,4-D/BAP at fiveto-one ratio) and concentration $\left(0.023,1.138,2.253,5.000\right.$ and $\left.10.000 \mathrm{mg} \mathrm{L}^{-1}\right)$ according to a multilevel factorial design (Table 2). The five-to-one ratio of 2,4-D and BAP hormones is recommended for high yield of secondary metabolites in vitro plant cell culture (Mustafa et al. 2011). Each Petri dish had five explants, and the experimental combinations were randomly performed in triplicate (48.89\%), in duplicate (37.78\%) and a single sample (13.33\%). The cultures were kept at $30^{\circ} \mathrm{C}$ for 30 days in incubator chamber to callus growth (Eletrolab, model EL101/3, São Paulo, Brazil).

\subsection{Extracts}

Each Petri dish with viable calli, they were frozen and lyophilised (LIOBRAS, model Loitop L101, São Carlos, Brazil) ( $24 \mathrm{~h}-36 \mathrm{~h}$ ) to obtain the dry mass. Then it was macerated with $\mathrm{N}_{2(\mathrm{l})}$ $(77 \mathrm{~K})$ to obtain the vegetable powder. The solutions were prepared in the ratio of $5 \mathrm{mg}$ (powder) per $1 \mathrm{~mL}$ in ethanol $70 \%\left(\mathrm{v} \mathrm{v}^{-1}\right)$. Then, they were put in an ultrasound bath (seven minutes at $30 \mathrm{kHz}$ ), and hereafter, they were centrifuged for $15 \mathrm{~min}$ at $2000 \mathrm{rpm}$ (QUIMIS, centrifugal microprocessor, model: Q222TM216, Diadema, Brazil). The supernatant was used for the chemical assays. 


\subsection{In vitro antioxidant activity}

The in vitro antioxidant activity was determined using the 1,1-diphenyl-2-picrylhydrazyl (DPPH) methodology described by Blois (1958) with modifications. In each tube was added absolute ethanol, acetate buffer $(100 \mathrm{mM} \mathrm{pH} \mathrm{5.5)}$ an ethanolic solution of DPPH (500 $\mu \mathrm{M})$ and the sample. The samples quantifications were done in triplicate and the absorbance values were expressed as percentage by the following Equation (1):

$$
\% \mathrm{AA}=\left[\frac{\left(A_{\mathrm{C}}-A_{\mathrm{S}}\right)}{A_{\mathrm{C}}}\right] \times 100
$$

where $\% \mathrm{AA}$ is the antioxidant activity, $A_{\mathrm{C}}$ is the control absorbance and $A_{\mathrm{S}}$ is the sample absorbance.

\subsection{Quantification of callus wet weight and budding index}

The budding index (\%) was determined to characterise the effectiveness of callus formation in each experimental condition; this parameter was defined considering explants number to callus number ratio. On the other hand, the wet weight of each callus was measured in analytical balance.

\subsection{Total phenol and flavonoid assays}

The content of total phenolic compounds was quantified using the Folin-Ciocalteu colorimetric method modified by Singleton and Rossi (1965), and the total flavonoids content was determined by Zhishen et al. method (1999). The samples were run in triplicate, and the results for total phenolic compounds and flavonoids were expressed as milligram gallic acid equivalent (GAE) per gram of dry weight of extract (mg GAE g ${ }^{-1} \mathrm{DE}$ ), and the rutin equivalent per gram of dry weight of extract ( $\mathrm{mg} \mathrm{RU} \mathrm{g}^{-1} \mathrm{DE}$ ), respectively.

\subsection{Statistical analysis}

Experimental planning and data analysis from multilevel factorial design were carried out in Design-Expert software (Trial version 10.0.3.1, Stat-Ease, MN, USA). The optimisation of callus culture variables was done using Derringer and Suich's desirability function (Costa et al. 2011) implemented in the same software.

\section{Conclusion}

This work is likely one of the first studies that uses a systematic approach to describe and optimise callus culture stage to initiate a long-term culture with potential pharmaceutical properties using a widely consumed pepper (C. baccatum). The flavonoid and total phenol content showed a direct relationship with the callus antioxidant properties. The hypocotyl explant in combination with 2,4-D/BAP (5:1 ratio) at $1.138 \mathrm{mg} \mathrm{l}^{-1}$ showed the best callus mass values. However, the multiple optimisation considering callus mass simultaneously, total phenols, flavonoids and antioxidant activity resulted in the following combination of factor: root explant, benzylaminopurine hormone at $1.138 \mathrm{mg} \mathrm{l}^{-1}$. 


\section{Acknowledgements}

The first author would like to thank the scientific teams from Laboratório de Biotecnologia Vegetal, Laboratório de Fitoterápicos e Produtos Naturais (FITOLAB) and Laboratório de Bioprocessos (UNESP, Campus Assis), mainly Tárik Heluy Reis and Rodrigo Boccoli Gallego for their significant technical support and friendship.

\section{Disclosure statement}

No potential conflict of interest was reported by the authors.

\section{Funding}

This work was supported by Fundação de Amparo à Pesquisa do Estado de São Paulo/Brazil (FAPESP) [grant number Master's fellowship 2014/26997-4].

\section{ORCID}

Eutimio Gustavo Fernández Núñez (D) http://orcid.org/0000-0002-2800-392X

\section{References}

Bertao MR, Moraes MC, Palmieri DA, Pereira Si L, Goncalves RM. 2016. Cytotoxicity, genotoxicity and antioxidant activity of extracts from Capsicum spp. Res J Med Plants. 10:265-275.

Blois MS. 1958. Antioxidant determinations by the use of a stable free radical. Nature. 181:1199-1200.

Costa NR, Lourenço J, Pereira ZL. 2011. Desirability function approach: a review and performance evaluation in adverse conditions. Chemom Intell Lab Syst. 107:234-244.

George EF, Hall MA, Klerk G-J De. 2008. Plant growth regulators II: cytokinins, their analogues and antagonists. In: George EF, Hal MA, Klerk G-J De, editors. Plant propagation by tissue culture. Vol. 1, The background. 3rd ed. Dordrecht: Springer; p. 205-226.

Kothari SL, Joshi A, Kachhwaha S, Ochoa-Alejo N. 2010. Chilli peppers - A review on tissue culture and transgenesis. Biotechnol Adv. 28:35-48.

Krishnan V, Ahmad S, Mahmood M. 2015. Antioxidant potential in different parts and callus of Gynura procumbens and different parts of Gynura bicolor. Biomed Res Int. 2015: Article ID 147909. doi: 10.1155/2015/147909

Malik S, Cusidó RM, Mirjalili MH, Moyano E, Palazón J, Bonfill M. 2011. Production of the anticancer drug taxol in Taxus baccata suspension cultures: a review. Process Biochem. 46:23-34.

Matkowski A. 2008. Plant in vitro culture for the production of antioxidants - A review. Biotechnol Adv. 26:548-560.

Motamedi J, Zebarjadi A, Kahrizi D, Salmanian AH. 2011. In vitro propagation and Agrobacterium -mediated transformation of safflower (Carthamus tinctorius L.) using a bacterial mutated aro $A$ gene. Aust J Crop Sci. 5:479-486.

Mustafa NR, de Winter W, van Iren F, Verpoorte R. 2011. Initiation, growth and cryopreservation of plant cell suspension cultures. Nat Protoc. 6:715-742.

Petrussa E, Braidot E, Zancani M, Peresson C, Bertolini A, Patui S, Vianello A. 2013. Plant flavonoidsbiosynthesis, transport and involvement in stress responses. Int J Mol Sci. 14:14950-14973.

Ramkissoon JS, Mahomoodally MF, Ahmed N, Subratty AH. 2013. Antioxidant and anti-glycation activities correlates with phenolic composition of tropical medicinal herbs. Asian Pac J Trop Med. 6:561-569.

Ranilla LG, Kwon YI, Apostolidis E, Shetty K. 2010. Phenolic compounds, antioxidant activity and in vitro inhibitory potential against key enzymes relevant for hyperglycemia and hypertension of commonly used medicinal plants, herbs and spices in Latin America. Bioresour Technol. 101:4676-4689. 
Schmitz C, Fritsch L, Fischer R, Schillberg S, Rasche S. 2016. Statistical experimental designs for the production of secondary metabolites in plant cell suspension cultures. Biotechnol Lett. 38:20072014.

Singleton VL, Rossi JA. 1965. Colorimetry of total phenolics with phosphomolybdic-phosphotungstic acid reagents. Am J Enol Vitic. 16:144-158.

Verma N, Shukla S. 2015. Impact of various factors responsible for fluctuation in plant secondary metabolites. J Appl Res Med Aromat Plants. 2:105-113.

Were BA, Gudu S, Onkware AO, Carlsson AS, Welander M. 2006. In vitro regeneration of sesame (Sesamum indicum L.) from seedling cotyledon and hypocotyl explants. Plant Cell Tissue Organ Cult. 85:235-239.

Zhishen J, Mengcheng T, Jianming W. 1999. The determination of flavonoid contents in mulberry and their scavenging effects on superoxide radicals. Food Chem. 64:555-559.

Zimmer AR, Leonardi B, Miron D, Schapoval E, Oliveira JR De, Gosmann G. 2012. Antioxidant and anti-inflammatory properties of Capsicum baccatum: from traditional use to scientific approach. J Ethnopharmacol. 139:228-233. 